\title{
Negotiating the Digital Vā: Emerging Pacific Scholars and Community Building on Twitter
}

\author{
Seuta'afili Patrick Thomsen, Lana Lopesi, Gregory Pōmaika'i Gushiken, Leah Damm, Kevin \\ Lujan Lee, Emmaline Pickering-Martin, Fetaui Iosefo, Sereana Naepi, Litia Tuiburelevu
}

\begin{abstract}
Although the power of social media to bring people together across borders is acknowledged, very little has been written about the potential of social media sites for emerging Pacific scholars living transnationally across our region and beyond. We deploy thematic talanoa to demonstrate how emerging Pacific scholars engage Twitter as a platform where routes and relationships are established and teu/tauhi in the digital vā. Furthermore, we argue that emerging scholars of Pacific heritage are building an augmented reality founded on Pacific-specific ways of relationship building, forming external to, and in response to, marginalising dominant narratives inside and outside Pacific worlds.
\end{abstract}

\section{Introduction}

Social media is an omnipresent force that pervades nearly all forms of modern life. Music stars are born on YouTube, modelling and makeup artist careers are made at the click of a button on Instagram, or lost at the conclusion of an overly polemic Facebook post. Twitter as a social media staple is made up of two key features: first, that of microblogging, which allows users to post status updates; and second, a follower system where users can subscribe to the microblogs of other users. ${ }^{1}$ The site was originally designed to encourage people to answer the question "what are you doing?," resulting in assembled digital personhoods. User responses-colloquially known as "tweets"- have evolved over time and developed in divergent and differentiated ways.

In this paper, we as a group of emerging scholars of Pacific heritage, located in disparate yet still connected locations, explore the ways we have used Twitter as a site to develop a community of Pacific scholars formed through innate understandings and centring of Pacific values in relationship building. In doing so, we add to a growing field of scholarship that demonstrates how the vā and constructing relational identities/communities can be achieved through digital platforms. We also suggest that sites like Twitter offer a digital interface where routes and connections between Pacific peoples around and through our region, interrupted through colonialism and empire, can be re-established and produce real life friendships, relationship, and kinship affective ties that transfer into real life. In doing so, we accept Nathan Jurgenson's conceptualisation of augmented reality, which sees our online and offline lives as connected. ${ }^{2} \mathrm{We}$ further argue that the way these connections are predicated on the wholeness and totality of Pacific experiences and reality are innately understood by other scholars of Pacific heritage.

To build this paper's core arguments, we present a thematic talanoa constructed through an exploration of the experiences of emerging scholars of Pacific heritage in using Twitter as part of their everyday lives. ${ }^{3}$ We asked the paper's collaborators to describe what their motivations were for joining the site, how they met other Pacific scholars, what they learned from using the site, and what value personally and professionally the site offered them. In deploying a thematic talanoa, this paper centres the words of collaborators in its pages, whilst theory and interpretations are built 
around them. Our arguments in this paper will orbit around the following three themes: encounters/wayfinding; connecting, relationality and establishing vā in building meaningful communities; and opportunities, tautua and the limit of communities. We conclude with a short discussion that outlines some of the wider implications of this paper's findings.

\section{Literature Review}

Pacific academic communities are part of global intellectual worlds, which consist of international travel circuits for academic programmes, conferences, and fieldwork. These international circuits are well marked for their importance in building the academic communities of early career researchers, and arguably in the case of emerging Pacific scholars create an "enlarged world of Oceania."4 Taking Nathan Jurgenson's notion of augmented reality that does not separate our on and offline lives but rather sees them as organically connected whether we are in front of or "away from keyboard" (AFK), we can expand these circuits for developing professional communities to the online environment, building on Lana Lopesi's claim that "Moana peoples have found opportunities" to build and connect on the internet. ${ }^{5}$

Emerging Pacific scholars building networks online has an early precedent through the chat room The Kavabowl, which was attached to the website The Pacific Forum and founded in 1995 by Taholo Kami during his studies in the United States. As an early outlier, The Kavabowl was soon followed by Polynesian Cafe, another chat room at this time run by $\mathrm{Al}$ and Sue Aiono out of Los Angeles. ${ }^{6}$ Both sites were incredibly popular amongst Pacific people globally, providing a unique place where discussions around culture broadly speaking could happen between internationally spread Pacific people at a scale and accessibility not before seen. This foreshadowed very early on the importance the internet and social media would play in routing and connecting Pacific peoples from across and beyond the region to each other.

Facebook, in particular, has since gained prominence as a space for emerging Pacific scholars to build networks. One highly successful example is The Pacific Scholars Facebook page, which currently has over 5000 members and is dedicated to building a community of Pacific researchers and graduate students. COVID-19 and its grounding of the usual global circuits - such as physical travel for conferences, field work and so on-has renewed the importance of social media and the online environment for emerging Pacific scholars, with organisations such as the South Pacific Islanders Organisation moving their yearly gathering to an online platform, which enabled an astonishing audience of 12,000 people.

\section{Digital $\boldsymbol{V} \overline{\boldsymbol{a}}^{7}$}

The way in which Pacific social worlds are maintained online despite physical distance points to trends in literature on Pacific internet and social media use, which focuses connectivity through Indigenous Pacific concepts such as vā. ${ }^{8}$ Toeolesulusulu Damon Salesa acknowledged the internet as obliterating distance and enabling key familial relationships to be newly empowered. ${ }^{9}$ This emphasis on both distance and connectivity is pertinent for a global population spread wide. Social media can offer a cheap and fast way to reinvigorate kinship relationships that may not be otherwise possible. ${ }^{10}$ Thus, social media sites are places of gathering.

For Pacific people, the "purposeful use [of social media] to connect peoples who through processes of colonisation, migration and assimilation have been disconnected reminds us of their 
effectiveness in imaging an Oceania."11 This paradigm of "Earth, ocean, heavens, cyberspace"12 has also been described as digital vā. ${ }^{13}$ Within the digital vā, the connectivity enables a collectivity mediated through relationality or vā relations, which plays a role in building both community and multi-layered Pacific identity narratives. ${ }^{14}$ Tiresa Po'e's study on transnational Samoan Facebook use found that "the practice of teu le va is a prime example of how Samoans are using Facebook as a tool to continue pre-existing Samoan behaviours." 15 Despite these ground-breaking and pivotal studies on Pacific communities, vā, and social media use, there is still little research on how digital vā is enacted on Twitter, and specifically how it relates to emerging Pacific researchers.

\section{Pacific Twitter}

To date there has been very little focus on Pacific Twitter use. ${ }^{16}$ Lana Lopesi focused on Twitter (or Poly Twitter as it is colloquially and problematically known) as a site in which "Moana publics" become apparent through shared imagery, language and concerns. An element of publics can be found on most social media sites; however, the following and follower system of Twitter (as opposed to network of friends) builds people into a community "who not only would never exist as a community in real life but also would never geographically be able to come together." ${ }^{17}$ Moana publics offer an opportunity to find your people through "colloquial and shared identities, which are connected to our homelands and to urban environments, are formed or imagined through languages and codes." 18 Drawing on the collectivity element in the Pacific internet literature, Moana publics on Twitter are a kind of ethnoscape or digital community defined by its potential for social reproduction. ${ }^{19}$

The significance of Twitter for Pacific people-as shared with other racialised Twitter communities - has a lot to do with the Eurocentric dominance of mainstream discourse, in places like the media but also the university. Twitter, a social network with an inbuilt distribution network, can offer those not traditionally well represented a platform and an audience. Anecdotally, Pacific Twitter use is galvanised often in resistance to being subsumed within dominant narratives surrounding political or social events, in which mainstream media coverage does not encompass divergent Pacific world views. Recent examples include Israel Folau's homophobic comments; the ongoing impacts of tourism to Hawai' $\mathrm{i}$; racist comments from Heather Du Plessis-Allan about Pacific contributions to New Zealand; and the current protection of Mauna Kea. In this vein, Pacific Twitter use can be understood as carrying counterpublic qualities. ${ }^{20}$

\section{Double-edged Sword}

While the radical potential of Twitter for emerging Pacific researchers is acknowledged, the digital world can be understood as a double-edged sword, which replicates the physical world that created it. $^{21}$ As a tool born from United States industrialisation and militarisation, the digital environment holds the same colonial, capitalist dynamics of the physical world because it is built on a tradition of knowledge production "deeply implicated in both colonialism and neocolonialism." 22 Thus, "unthinkingly, without malice" and because of a lack of critique the hallmarks of colonialism are being moved over into the digital space. ${ }^{23}$ Pacific internet users must understand and to some extent conform to the "architecture (and all of its limitations and restrictions) of the space," its systems and its structures. ${ }^{24}$

Discussing emerging Pacific researchers finding a digital vā on Twitter also raises the question of echo chambers - a popular criticism of all social media sites. Because of the personalisation of our

Journal of New Zealand Studies NS33 (2021), 140-152 https://doi.org/10.26686/jnzs.iNS33.7388 
social media accounts, users seek out other users who share their ideologies. However, more recently, it has been thought that the impact of "echo chambers in social media has been highly over-estimated," as studies have shown that social media users actually do seek information outside of their own political beliefs. ${ }^{25}$ Also, the role of echo chambers in building community among marginalised groups who sit outside hegemonic narratives and identities is not a point this scholarship is particularly attuned to. This is important, as will be demonstrated through this paper. For emerging Pacific scholars these curated communities, much like an echo chamber, formed sites of resistance that became crucial for personal safety and survival.

\section{Research Procedure}

Talanoa - the ongoing discussion in relational space - is an established Pacific methodology to maintain vā. ${ }^{26}$ Moreover, it is a core part of networking for emerging Pacific scholars. For Pacific peoples, experiences are not discrete data; rather, they are part of a larger genealogy of woven relationships that require further contextualisation and cultural sensitivity to understand. This paper uses a model established by the first Pacific Early Career Academics Network (PECAN) at the University of Auckland, created to build supportive and collaborative writing relationships with each other as a way to disrupt the pressure academia imparts to publish alone. ${ }^{27}$ For a new generation of Pacific scholars, where collaboration is more highly valued and can be more easily facilitated through expanding technologies, establishing and maintaining vā is very meaningful. Neoliberal values drive measures of academic capital that are centred on individual output, which can sit in opposition to Pacific values of collaborative, relational and culturally-appropriate ways of knowing and working. ${ }^{28}$ Rather than smoothing over different experiences found amongst this network of emerging Pacific academics, this methodology enables the productive tensions between each of the collaborators to be seen, moving away from homogenising tendencies.

As emerging Pacific scholars, we can challenge the divisive nature of academic spaces by dialoguing with each other and with research by our Pacific academic elders to collaborate on research, career and skills development, as well as building meaningful relationships despite differences in disciplines, schools, faculties, and continents. This relational praxis offers a way to move beyond the traditional hierarchies of academia and, as will be argued, mirrors the importance of counterpublics such as Twitter for emerging Pacific researchers. All named authors of this paper are of Pacific heritage, based in New Zealand and the United States. Furthermore, all scholars involved in this publication came to know each other through Twitter in either a professional or personal capacity.

Our methodology and methods were developed within this context. Like other articles produced by the PECAN, our contributors answer questions within a collaborative, iterative document, a process that we have likened to a written talanoa. ${ }^{29}$ These questions centred around what motivated collaborators to join Twitter, how they encountered each other, what typical interactions they had on the site, and how they used the site to build relationships. They were also asked about positive and negative experiences of using the platform, and what lessons they believed we could learn as scholars from using Twitter. The responses received from nine collaborators were collated, coded openly, and then arranged into themes. They were subsequently axially coded and then underwent a thematic analysis that is presented here as a thematic talanoa. ${ }^{30}$ The key themes identified were (1) encounters/wayfinding; (2) connecting, relationality and establishing vā in building meaningful communities; and (3) opportunities, tautua and the limit of communities. The paper concludes by

Journal of New Zealand Studies NS33 (2021), 140-152 https://doi.org/10.26686/jnzs.iNS33.7388 
arguing that although Twitter as a site has problematic origins and structures that undergird its infrastructure as a technology, emerging scholars of Pacific heritage have used the site to reestablish and re-route connections that enable them to build community in Pacific ways through the digital vā across national borders.

\section{Thematic Talanoa}

\section{Theme One: Encounters/Wayfinding}

Many collaborators were unsure as to when and why exactly they joined Twitter. For those who were sure, their reasons ranged from escaping family on Facebook, to finding solace in a platform that allowed them to dump views into the void anonymously. They often found their way to Twitter not by design, but rather because of some type of life event, including being based offshore, a significant media event, or through recommendations by others. When these recommendations did come, they were offered usually by friends and mentors. For our collaborators in the United States, Twitter was identified early on as a venue where academic networking could take place.

I've been on Twitter for about 9 years and honestly, I cannot remember why I joinedmost likely just following the social media trends. Once I did join though I enjoyed the kind of anonymity that Twitter offered. My Twitter social world was one I could build rather than one based on family and friend networks, so the idea of screaming into the void with somewhat like-minded people was a big draw card.

I joined Twitter for the first time around 2010. At the time I was very unfamiliar with the format and struggled to understand "microblogging" having only really been exposed to the broader sphere of Facebook. I became more active on the platform around 2012/2013, which coincided with the hypervisibility of "social media justice." It was this era that birthed movements like Black Lives Matter, Occupy Wallstreet, and the Arab Spring.

My Twitter life began when I was in South Korea and entering graduate school for the first time. I signed up for a Twitter account around 2010 as I wanted to get away from my family's oversharing and embarrassing Facebook posts, which was beginning to limit the way I was able to share my opinions and points of view as I diverge significantly from the rest of my family in the way I think and speak.

I started Twitter in 2018, right when I was starting my PhD program, mostly because I learned that Twitter was the new site for academic networking. I followed a bunch of professors and $\mathrm{PhD}$ students whose work I had been following, and Twitter quickly became an easy tool to discover other scholars and practitioners doing interesting, related work.

Collaborators indicated that after they familiarised themselves with the way the site operated, they navigated toward other users that they found who were tweeting about experiences they were also wayfinding through. For our women collaborators, a common theme was the shared experience of entering motherhood; for some it was the energy of cultural commentary and sociopolitical discourse on controversial issues; and for others it was a shared taste in music. Notably, Pacific experiences of motherhood and Pacific perspectives on sociopolitical issues sit outside of

Journal of New Zealand Studies NS33 (2021), 140-152 https://doi.org/10.26686/jnzs.iNS33.7388 
dominant conversations on both topics; thus, the kind of public commons where Pacific people share these perspectives does not exist in the same way in other places. All collaborators found themselves gravitating toward other Pacific users organically connecting because of shared experiences and values beyond just a professional or networking function:

The enormity of Twitter is such that it is quite easy to find a community that meets one's social needs. Which for me, occasionally meant connecting with other mothers. In a pragmatic sense, this gave me some support in being a first-time parent. Moreover, it exposed me to the discursive shifts in global and identity politics. My entry into motherhood made sense of my identity, my womanhood, something of an epistemic journey. As it turned out, my "epistemic journey" was not unique and I found myself connecting with other Pacific academics, artists, and community members who shared similar journeys.

I just finished my comprehensive exams in May 2020 and had a few weeks where I was actively thinking through my dissertation topic and learning a lot more about our MoanaOceania region. I found the Twitter accounts of a bunch of economists and policy wonks - all of them White, none of them who were talking about the role that Pacific Islanders should play in development planning in their own homelands. I came across @_PatrickThomsen, was intrigued by his work with the Human Rights Measurement Initiative and was sold by our shared love for Mariah Carey. Our initial Twitter exchanges were all centred on Mariah Carey, which prompted more conversations, and ushered in our current collaborations!

There was controversy about Israel Folau and his homophobic statements. At the time I was fuming but could not express myself without looking like the "angry brown mother of a gay son." A friend of mine forwarded me through a tweet from the handle @ touchmypoly. Here was an openly gay Poly man standing in the gap for me and my son. At the time I was lost in the rage and hurt of Israel Folau's comments that I had no words yet a world away @ touchmypoly was using this conduit of Twitter to speak up for himself and unbeknown to him speak also for me. I was floored with the connection I felt to this invisible entity. This feeling of validity and being seen began to resonate deeply within my soul. Of course his love for his muse Mariah Carey was a shared connective delight.

Collaborators were drawn into using the platform through the relatability and shared interests they were finding across the site with other Pacific users. This is important, as their initial hesitation with navigating microblogging was overcome through personal connection. In the second theme, we delineate specifically how the Pacific way that collaborators built community is rooted in Pacific values, ways of knowing, relating and shared experiences of otherness that heighten the depth and the criticality of these communities that speak to strategies of survival.

\section{Theme Two: Connecting, Relationality and Establishing Vā in Building Meaningful Communities}

Collaborators built a sense of community through connection to online personas that encompassed the full spectrum of Pacific humanity. There was an integrity in the connections that collaborators built that they all sensed was based on shared experiences of exclusion and otherness in

Journal of New Zealand Studies NS33 (2021), 140-152 https://doi.org/10.26686/jnzs.iNS33.7388 
mainstream spaces often tied to professional networks as rising scholars. Additionally, they felt otherness from dominant discourses within Pacific and Indigenous communities that marginalised internally those who did not fit hegemonic narratives. This was illustrated in the Israel Folau case and the erasure of Pacific women in the example of motherhood. The takeaway from these reflections was that while community was being built on shared genealogical and intellectual connections, experiences of marginality also mattered, including an acknowledgement of colonisation, which facilitated the urgency to establish and teu or tauhi relationships in the digital vā:

I think what drew me to following @touchmypoly was his analysis and how he was engaging in the discourse in general, but it was also the personality that Twitter allowed. The people that I developed relationships with are the ones who were their whole selves, in some sense. I think of queer Latinx scholar Deborah Vargas's 2014 study of LGBT gentrification of "dirty" spaces - spaces where queers of colour are allowed to be who we are in all our complexities, histories, and politics - for the sake of presenting "a clean body and a clean mind [as] attributes of a good citizen."

I distinctly remember seeing @beingahouse and @lana_lopesi posting about becoming a mum for the first time and I was of course instantly drawn to this. There is something ridiculously soothing about seeing other Pacific Māmā sharing their journeys because it is never an easy road. @ beingahouse blogged about her pregnancy and I loved every word relating in so many ways. @lana_lopesi would tweet little random thoughts about her daughter and I could almost hear myself in her words.

I often find that relationships with other Pacific scholars through Twitter are intrinsically tied by a shared eagerness for knowledge. This is distinct from the pursuit of knowledge as per the imperialist imagination that seeks to appropriate. Rather, I find the networks of Pacific scholars that I've been fortunate to connect with, are all engaged in the same pursuit - to make sense of the contemporary world for the betterment of our Indigenous communities.

These connections for collaborators often shifted to what Nathan Jurgenson calls AFK, where many now consider their Twitter connections as close friends and family. This was explained because of finding comfortability with people who shared a shorthand in their lived experiences as embodying continued erasure and marginality. ${ }^{31}$ Many felt safety, connecting on a personal level with others in this way. Others also felt a connection to the power of living open, uncensored personas online. This was also seen as a statement of defiance around the tendency for academia to pressure budding scholars into developing respectable and performative public images, especially online:

I consider @ touchmypoly and @ mebeemz some long-term personal friends that I have connected with through Twitter. Our friendship is mostly maintained through cyberspace given that we all reside on separate sides of the city, and at one point were a transnational network with@ @touchmypoly living in South Korea. But in the few instances that @ touchmypoly would return home, a group of us would head out South and spend an evening in hyena-pitched laughter and talanoa.

Journal of New Zealand Studies NS33 (2021), 140-152 https://doi.org/10.26686/jnzs.iNS33.7388 
Over the years@_patrickthomsen, @mocedoce, @lana_lopesi, among others within our networks, have been a significant support network for my personal and professional lifean incredibly important thing to have as a marginalised identity in the contemporary academic space. I think the latter is somewhat a bolster to our solidarity with one another. Not to limit our bonds as defined solely by struggle - especially because we are all unique and diverse in our identities and experiences.

I think there's often a demand by academia to "clean up" spaces like Twitter. We were told from a young age that we need to closely monitor our internet presence, that we need to portray a "professional" persona. We are expected to "clean up" the excess of our struggles, our memes, our shitposts, our jokes, our frustrations, our authentic connections. These "cleanup efforts" are almost always in service of a colonial agenda that seeks to reduce us to a flat "professional" persona. What drew me to @ touchmypoly's tweets was complexity. Whether it was tweeting about everyday struggles of having to make ends meet, of writing a dissertation, of dealing with interns that he supervised, or of engaging with the latest issue that came up on \#PolyTwitter.

For collaborators, Twitter as a platform allowed them to lay bare the wholeness of their experience as Pacific, Indigenous, and often marginalised scholars among academic communities that expected assimilation. The relationships that collaborators built can be seen here as defiant in their refusal to play into respectability narratives, and despite often being brought together through shared experiences of marginalisation, these relationships were not defined by otherness. Rather, collaborators built vibrant expressions of life in its entirety, which they nurtured and developed further AFK.

\section{Theme Three: Opportunities, Tautua and the Limit of Communities}

As Pacific and Indigenous people, living on Teaiwa's edges, many collaborators built real connections across the region whilst feeling displaced from home, leveraging their connections in tautua or service of wider community groups through their scholarship. ${ }^{32}$ The connections built through Twitter also brought many opportunities to learn from senior scholars or to reshape projects, and also brought material benefits such as publishing and collaboration opportunities. One collaborator even secured a permanent academic position through Twitter communities:

It was through Twitter where editors and journalists would learn about the work I was doing. It led me to being commissioned to write pieces for different publications whilst based in Seoul and Seattle. A senior Pacific academic had been following me for a while and pushed me to apply for postdoctoral roles with their endorsement and support which I landed and returned to New Zealand. Now, I've been offered on-going external engagements that include working with New Zealand broadcasting groups, publishers, industry, government and I've leveraged my Twitter networks to help facilitate even stronger connections on the ground with other emerging Pacific scholars in New Zealand universities and within my own to work together in strengthening our presence and service to our communities.

I've lived outside of Hawai' $i$ for a few years now, and I would argue that connecting with others through Twitter is the only way that I've stayed in my program. Although I am fortunate to be in a PhD in Ethnic Studies, which considers the intersections of race, class, 
gender, and sexuality, there are discussions that can only be had within our own community. It has been through these connections on Twitter that I've been able to grow and push myself. I ended up joining a Pacific Studies reading group out of Australia with a bunch of Pacific scholars during COVID, and I think that my project would simply not be in the place it is right now if one of them didn't tell me directly that what I was saying was in conflict with a lot of conversations within Pacific Studies.

Twitter has fostered an interdisciplinary approach that is necessary to take on the big challenges in our communities. It has also helped me to untrain some of the NorthAmerican training I received. Twitter is about relationships and because of that it enhances my ability to guide my scholarship through relationships, it is about how we uplift each other, and that can be as simple as sharing one of our community's papers with the world, choosing to write together or sending a DM when we see somebody is having a tough time.

My understanding of Pacific issues, both contemporary and historic, was often filtered through a single, academic (colonial) framework. Engaging with numerous Pacific scholars (including academics, writers, artists, students) the world over reminds me of the diversity in our thinking; that while there's issues affecting the "collective" we can't be homogenised as though we're a singular vat of chocolate milk. My critical thinking skills have improved, especially in terms of approaching issues with nuance. I see many of the Pacific scholars I follow as my tuākana and truly value their input, insights and interactions. It's also heartwarming how Pacific scholars use Twitter to actively support each other's academic outputs/writing/mahi_-generating both exposure and community empowerment.

For collaborators, it was obvious that Twitter brought them many opportunities for paid work, as well as personal and professional development through these connections formed in the digital vā. However, there was a strong sense that the term networking in Euro-American contexts was not adequate to capture the full richness of these connections. For collaborators, the relationships were relational, reciprocal, generous and prefaced on continuing or reviving genealogical connections to our peoples and region. This is what made these connections uniquely Pacific specific. For some, these connections literally brought them to an ontological and epistemological awakening around Pacific ways of knowing that they had not been exposed to in their prior academic training: Twitter has meant that I have been able to secure paid work outside of my academic work. It has meant that I have been able to gain writing jobs and consultancy work. It has opened my networks across Pacific areas including media, television, radio and internationally, too. Aside from this, it has helped build a friendship group that I can rely on consistently if I am struggling in any way shape or form. Some of my closest connections have been made through Twitter and these have translated into my real life as well both personally and financially. I have also been able to share my friends with my contacts and get them paid work also.

I think that Twitter has been more than just a "networking" tool like many haole like to call it. The people I've met through Twitter are friends, community, allies engaged in study and struggle. I realised that my parents, grandparents, and great grandparents would never have even had the chance to engage with much less write, laugh, and build community with other Pacific people, much less other Hawaiians. Twitter is providing a critical point of 
connection for us. I think that Twitter has helped me re-establish critical webs of relations that have sustained me. And by that, I mean the relationships, rather than the platform of Twitter itself, have been nurturing, critical, and, perhaps, lifesaving, at times.

In the US, academia is shaped in large part by the tyranny of the impact factor. Through Twitter, and specifically through collaborations with some listed in this paper, I'm actively unlearning the many biases that I inherited through my narrow academic training, and am learning what it means to establish a truly transnational intellectual community-laying bare the kind of theoretical optics we all implicitly or explicitly adopt, and the kind of disciplinary dogma and norms we all unwittingly bring to the table. This is the challenge that is animating much of my intellectual growth at the moment, and it is very much a work in progress; I expect, however, that with time, I will become more attuned to recognising and embracing other ways of knowing.

Among collaborators there was also a reflexive recognition that the connections they built through Twitter complicated universalist narratives around a Pacific community in which all Pacific peoples were equally positioned. In fact, for some, their politics and their right to exist in their own truths could cause friction within the wider Pacific "community," which was so opaquely defined, yet quickly deployed as a weaponised group identity on social media. This is significant, as these divergences from hegemonic narratives demonstrate the complexity of Pacific communities that are made visible by collaborators being able to find each other using the digital infrastructure that Twitter provided. These reflexive ruminations also extended to academic spaces and to how being outspoken online, many felt, could have negative consequences on their future employability and ability to fit into community groups and narratives:

As someone who works at the already complicated intersections of queerness and Hawaiian indigeneity, I realise that much of what I write can often be too much of a "hot take" for people in our community, some of which result in real life repercussions. While of course it's nice to have people come up to you and say they've read your tweets, I've experienced my fair share of people treating me differently because of my public engagements with queerness. So, while I think that this kind of experience is frustrating, I suppose it's also made me realise who I claim as "community" doesn't have to be absolutely everyone who is Hawaiian.

I've come to understand that being very public on particular issues can make the university uncomfortable precisely because they are complicit in upholding uneven power relationships and can be marginalising to many of us who do not fit dominant narratives. The conundrum that I am negotiating is that academically, I grow as a scholar through the courageous conversations with others I develop through Twitter, but the generative edges of these conversations are potentially disruptive to the university's money-making model. Thus, I say that I could literally tweet myself out of a job one day.

\section{Conclusion}

This paper has demonstrated that emerging scholars of Pacific heritage, situated at and beyond the edges of our Moana-Oceania region, have used Twitter in ways that empower connection in building a digital vā. Collaborators found each other after wayfinding through an experience of initial confusion, encounters with masses of tweets and retweets, to ultimately build relationships

Journal of New Zealand Studies NS33 (2021), 140-152 https://doi.org/10.26686/jnzs.iNS33.7388 
founded on shared genealogical connection and experiences. These connections are meaningful and activated through not just narratives of struggle, but of liberation: of being able to build friendships to live out joyful and defiant experiences of community-building online. These connections are significant for these emerging scholars as it has helped them to access learning and employment opportunities, as well as collaboration opportunities such as the story played out in these pages.

Many collaborators believed Twitter had given them the opportunity to access knowledge from scholars and places they never dreamed would be accessible. This is an important point, as knowledge transfer in academia has often failed in its conventional forms to connect with Pacific communities. In this way, the site offers emerging scholars of Pacific heritage pathways to people and intellectual resources across regions, time zones, and diverse institutions that are empowering them as scholars, deployed through the use of Twitter (mostly) on their mobile phones. This accessibility to people, ideas, and networks is critical in helping to provide support and development opportunities to emerging scholars of Pacific heritage through collaboration.

As academia continues to grapple with the inefficiency and potential irrelevancy of its traditional forms of knowledge dissemination in long-winded and often overwrought prose in books and journal articles, social media sites like Twitter offer concise and compact avenues to share our research and work with our communities through microblogging. This is a space Pacific emerging scholars are well-positioned to take advantage of, in growing the reach, scope, and direction of Pacific research. This is especially important in light of the rising value of TikTok as a platform for driving public discourse on critical issues through short, user-modified, edited and produced videos that can often go viral in a matter of minutes and hours.

Although these stories of empowerment speak to the realm of generative possibilities for marginalised groups to congregate, connect and resist online, collaborators also acknowledge that there are deeper material aspects that have not been dealt with adequately in this article. Consider the significance of underwater cables that stretch across the Moana: that the internet was developed to advance American militarism that still bombs our oceans and islands. Connectivity is only possible through the incredible disconnection and unfreedom of certain places and peoples. Further, like other spheres of bourgeois Western sociability, Twitter and the internet more broadly demand us to contend with the reprisal of anti-Black colonial discourses rooted in the dispossession of Indigenous land, chattel slavery, indentured labour, and various other violences that stretch across four continents, and make possible the technologies that allow us to build community across the Moana. ${ }^{33}$

Whilst acknowledging the violences required for these technologies to function, we can also build relationships and hopes in spite of it. All collaborators acknowledge that although Twitter was sometimes a problematic platform, it is not Twitter but the routes and paths that our Pacific community have made across the site that realises the potential of the technology. We end this paper with a reflection from a collaborator who asks us to think about the community-building capacity of Twitter as an in spite of rather than a because of. As Lana Lopesi argues, the concept of representation on the internet is a double-edged sword. ${ }^{34}$ As we enter a double-bind of representation where these material conditions need to be contended with, we can understand that this discussion reaches a productive tension rather than an impasse. Tension is good, tension binds

Journal of New Zealand Studies NS33 (2021), 140-152 https://doi.org/10.26686/jnzs.iNS33.7388 
us, and tensions are generative, forcing us to think strategically and inclusively as we develop new possibilities through technologies like the internet and platforms such as Twitter.

\footnotetext{
${ }^{1}$ Courtenay Honey and Susan C. Herring, "Beyond Microblogging: Conversation and Collaboration via Twitter," in 2009 42nd Hawaii International Conference on System Sciences (New York: IEEE, 2009), 110.

${ }^{2}$ Nathan Jurgenson, "Digital Dualism Versus Augmented Reality," The Society Pages (24 February 2011), https://thesocietypages.org/cyborgology/2011/02/24/digital-dualism-versus-augmented-reality/.

${ }^{3}$ Sereana Naepi et al., "The Pakaru 'Pipeline': Māori and Pasifika Pathways within the Academy," The New Zealand Annual Review of Education 24 (2020): 142-59; Patrick S. Thomsen, "Coming-out in the Intersections: Examining Relationality in How Korean Gay Men in Seattle Navigate Church, Culture and Family through a Pacific Lens," Journal of Homosexuality 68, no. 6 (2021): 1015-36; Patrick S.

Thomsen, "Transnational Interest Convergence and Global Korea at the Edge of Race and Queer Experiences: A Talanoa with Gay Men in Seoul," Du Bois Review: Social Science Research on Race (2020): 1-18; Patrick Thomsen et al., "In Our Own Words: Pacific Early Career Academics (PECA) and Pacific Knowledges in Higher Education Pedagogical Praxis," Higher Education Research and Development 40, no. 1 (2021): 49-62; Patrick Saulmatino Thomsen et al., "Practising Pacific Pedagogies during New Zealand's Level Four Lockdown: Pacific Early Career Academics and COVID-19," Waikato Journal of Education 26 (2021): 149-61.

${ }^{4}$ Epeli Hau'ofa, "The Ocean in Us," The Contemporary Pacific 2 (1998): 392-410.

5 Jurgenson, "Digital Dualism Versus Augmented Reality"; Lana Lopesi, False Divides (Wellington:

Bridget Williams Books, 2018).

${ }^{6}$ Marianne I. Franklin, Postcolonial Politics, the Internet and Everyday Life: Pacific Traversals Online (Milton Park: Routledge, 2006); Damon Salesa, Island Time: New Zealand's Pacific Futures

(Wellington: Bridget Williams Books, 2017); Lopesi, False Divides.

${ }^{7}$ Digital vā as articulated in this paper is centred on a Samoan understanding of vā, rather than a Tongan one which has its own distinct position.

${ }^{8}$ Amy Jane Tielu, "Searching for the Digital Fāgogo: A Study of Indigenous Samoan Storytelling in Contemporary Aotearoa Digital Media" (MPhil exegesis, Auckland University of Technology, 2016); Tiresa Po"e, "Facebook and Fa'asamoa: Exploring the Expression of the Samoan Identity Online" (MA thesis, University of Auckland, 2017); Salesa, Island Time; Lopesi, False Divides.

${ }^{9}$ Salesa, Island Time.

${ }^{10}$ Lopesi, False Divides.

${ }^{11}$ Lopesi, False Divides, 102.

${ }^{12}$ Leah Damm, "Brown and Very Online," Essential Services Zine 3 (2020): 17-20, https://essentialserviceszine.com/file/Essential-Services-Zine_3.pdf.

${ }^{13}$ Cresantia F. Koya, "Cyberspace, Place, Identity and Relationships: Are We Digitizing the Vā?" (presentation at the International Conference on ICT and Oceanian Cultures, University of the South Pacific Laucala Campus, Suva, Fiji, 24 February 2012); Po'e, "Facebook and Fa'asamoa"; Marion Muliaumasealii, "The Space In-between: An Ethnographic Study of Mobile Technology and Social Change in Rural Samoa" (PhD dissertation, RMIT University, 2017); Damm, "Brown and Very Online"; Dion Enari and Jacoba Matapo, "Pasifika Education Innovation During the COVID-19 Pandemic," MAI Journal (2020): 7-11.

${ }^{14}$ Rosanna Raymond, "Conser. VĀ. tion| Acti. VĀ. tion Museums, the Body and Indigenous Moana Art Practice" (MPhil exegesis, Auckland University of Technology, 2021); Benita Simati-Kumar, "How Does the Next Generation of Pacific Diaspora from Blended Backgrounds Construct and Maintain Their Identities through the Spaces They Inhabit?" (PhD thesis, Auckland University of Technology, 2016);
} 
Sereana Naepi and Sam Manuela, "Rewriting the World: Pacific Peoples, Media and Cultural Resistance," in Global Handbook on Ethnicity, ed. Steven Ratuva (London: Palgrave-Macmillan, 2019). ${ }^{15}$ Po'e, "Facebook and Fa'asamoa," 94.

${ }^{16}$ Lana Lopesi, "Safety in Numbers: Poly Twitter and Carving Out Digital Space," The Pantograph Punch (10 May 2016), https://pantograph-punch.com/posts/safety-in-numbers-poly-twitter; Lopesi, False Divides; Lana Lopesi, "Making A Table: Moana Publics Online," in Public Knowledge, Radical Futures Series (Wellington: Freerange Press, 2020); Damm, "Brown and Very Online."

${ }^{17}$ Lopesi, "Making A Table," 82.

${ }^{18}$ Lopesi, "Making A Table," 51.

${ }^{19}$ Arjun Appadurai, Modernity at Large: Cultural Dimensions of Globalization, volume 1 (Minneapolis: University of Minnesota Press, 1996).

${ }^{20}$ Nancy Fraser, "Rethinking the Public Sphere: A Contribution to the Critique of Actually Existing Democracy," Social Text 25/26 (1990): 56-80; Michael Warner, "Publics and Counterpublics Zone Books," New York (2002).

${ }^{21}$ Lopesi, False Divides.

${ }^{22}$ Roopika Risam, New Digital Worlds: Postcolonial Digital Humanities in Theory, Praxis, and Pedagogy (Evanston: Northwestern University Press, 2018), 4.

${ }^{23}$ Risam, New Digital Worlds, 5.

${ }^{24}$ Acushla Deanne O'Carroll, "Kanohi ki te Kanohi-A Thing of the Past? An Examination of Māori Use of Social Networking Sites and the Implications for Māori Culture and Society" (PhD thesis, Massey University, 2013), 162.

${ }^{25}$ Elizabeth Dubois and Grant Blank, "The Echo Chamber is Overstated: The Moderating Effect of Political Interest and Diverse Media," Information, Communication and Society 21, no. 5 (2018): 729-45. ${ }^{26}$ Melani Anae, "Research for Better Pacific Schooling in New Zealand: Teu le Va-A Samoan Perspective." MAI Review 1, no. 1 (2010): 25; Sereana Naepi, "Pacific Research Methodologies," in Oxford Research Encyclopedia of Education (2019); David Fa'avae, Alison Jones, and Linitā Manu'atu, "Talanoa'i 'A e Talanoa-Talking about Talanoa: Some Dilemmas of a Novice Researcher," AlterNative: An International Journal of Indigenous Peoples 12, no. 2 (2016): 138-50; Timote M. Vaioleti, "Talanoa Research Methodology: A Developing Position on Pacific Research," Waikato Journal of Education 12 (2006): 21-34.

${ }^{27}$ Thomsen et al., "In Our Own Words," 49-62; Thomsen et al., "Practising Pacific Pedagogies during New Zealand's Level Four Lockdown," 149-61; Naepi et al., "The Pakaru 'Pipeline,"” 142-59.

${ }^{28}$ Mark Olssen and Michael A. Peters, "Neoliberalism, Higher Education and the Knowledge Economy: From the Free Market to Knowledge Capitalism," Journal of Education Policy 20, no. 3 (2005): 313-45.

${ }^{29}$ Naepi et al., "The Pakaru 'Pipeline,"” 142-59.

30 Thomsen, "Transnational Interest Convergence and Global Korea," 1-18; Thomsen, "Coming-out in the Intersections," 1015-36.

${ }^{31}$ Jurgenson, "Digital Dualism Versus Augmented Reality."

${ }^{32}$ Teresia K. Teaiwa, "L (o) osing the Edge," The Contemporary Pacific (2001): 343-57.

${ }^{33}$ Lisa Lowe, The Intimacies of Four Continents (Durham: Duke University Press, 2015).

${ }^{34}$ Lopesi, False Divides. 